\title{
UN RARO MOTIVO ICONOGRAFICO SULLA SCULTURA ALTOMEDIEVALE - I SENMURV DI ARBE E NEVIDANE
}

\author{
Miljenko Jurković
}

\author{
M. Jurković \\ University of Zagreb \\ Faculty of Humanities and Social sciences \\ Department of History of Art \\ Ivana Lučića 3, HR-10000 Zagreb \\ mjurkovi@ffzg.hr
}

In this paper the author deals with a fragmented early medieval altar screen slab from Rab. The focus of the analysis is a very rare motif in early medieval sculpture that has been identified - the senmurv. After giving a comparative analysis, the author adds the slab from Rab to the opus of the stone carving workshop called The Master of the Zadar Ambos, dating it at the very beginning of the $9^{\text {th }}$ century.

Key words: early medieval sculpture, iconography, senmurv, stone-carving workshops

Nel lapidario di Arbe è esposto un frammento di pluteo altomedievale recante una decorazione particolarmente interessante che tuttavia non ha mai destato una grande attenzione da parte degli studiosi. Del manufatto sono state pubblicate principalmente le immagini, senza qualsiasi approfondimento su origine, datazione e senza riferimenti con altri elementi dell'arredo liturgico con cui probabilmente costituiva un insieme ${ }^{1}$.

Si tratta di un terzo del lato destro di un pluteo, frammentato in alcune parti ricomponibili, che mostra uno schema compositivo costituito da una teoria di maglie quadrangolari triviminee collegate tra loro su ogni lato mediate un nodo (fig. 1a). Il nastro ai bordi della lastra collega tutti i rettangoli in un'unica composizione generando ritmicamente nodi che si annodano in corrispondenza di metà lato di ogni maglia quadrangolare. Del manufatto si conservano interamente due campi e la metà di un terzo che, tra l'altro, risulta il più interessante. Al centro di uno dei due rettangoli campiti da un nodo di Salomone, formato da nastro bisolcato, vi è un bottone. Il rettangolo marginale inferiore contiene i resti di una rappresentazione zoomorfa di cui è visibile il tratto inferiore del corpo di un animale con una grande coda piegata verso l'alto e un oggetto, solitamente identificato come una specie di "corona", sulla sommità della testa. Il pluteo frammentato è stato riportato in diverse pubblicazioni principalmente per illustrare la produzione lapicida altomedievale di Arbe. Tuttavia, prima di arrivare al lapidario il manufatto si presentava più completo. Infatti, sulla prima fotografia, pubblicata all'inizio del XX secolo da W. Schleyer senza alcuna interpretazione (fig. 1b) ${ }^{2}$, appare ancora integra l'interessante maglia angolare inferiore recante la rappresentazione zoomorfa. Si riconosce con chiarezza un animale con il corpo di uccello, ali chiuse, coda piegata all'indietro e disposta parallelamente alla spina dorsale e testa sormontata da una "corona". Dalla bocca fuoriesce un oggetto

\footnotetext{
* Questo lavoro è stato realizzato nell'ambito del progetto Croatian medieval heritage in European context: mobility of artists and transfer of forms, functions and ideas (CROMART), finanziato dalla Fondazione Croata delle Scienze.

${ }^{1}$ M. DOMIJAN, Rab, Citta d'Arte, Zagreb 2007, 51; T. MARASOVIĆ, Dalmatia praeromanica II, Split- Zagreb 2009, p. 125; M. JARAK, Starokršćanska i ranosrednjovjekovna skulptura otoka Raba, Starohrvatska prosvjeta 37/2010, p. 92.

${ }^{2}$ W. SCHLEYER, Arbe, Stadt und Insel, Wiesbaden, 1914, p. 117.
} 

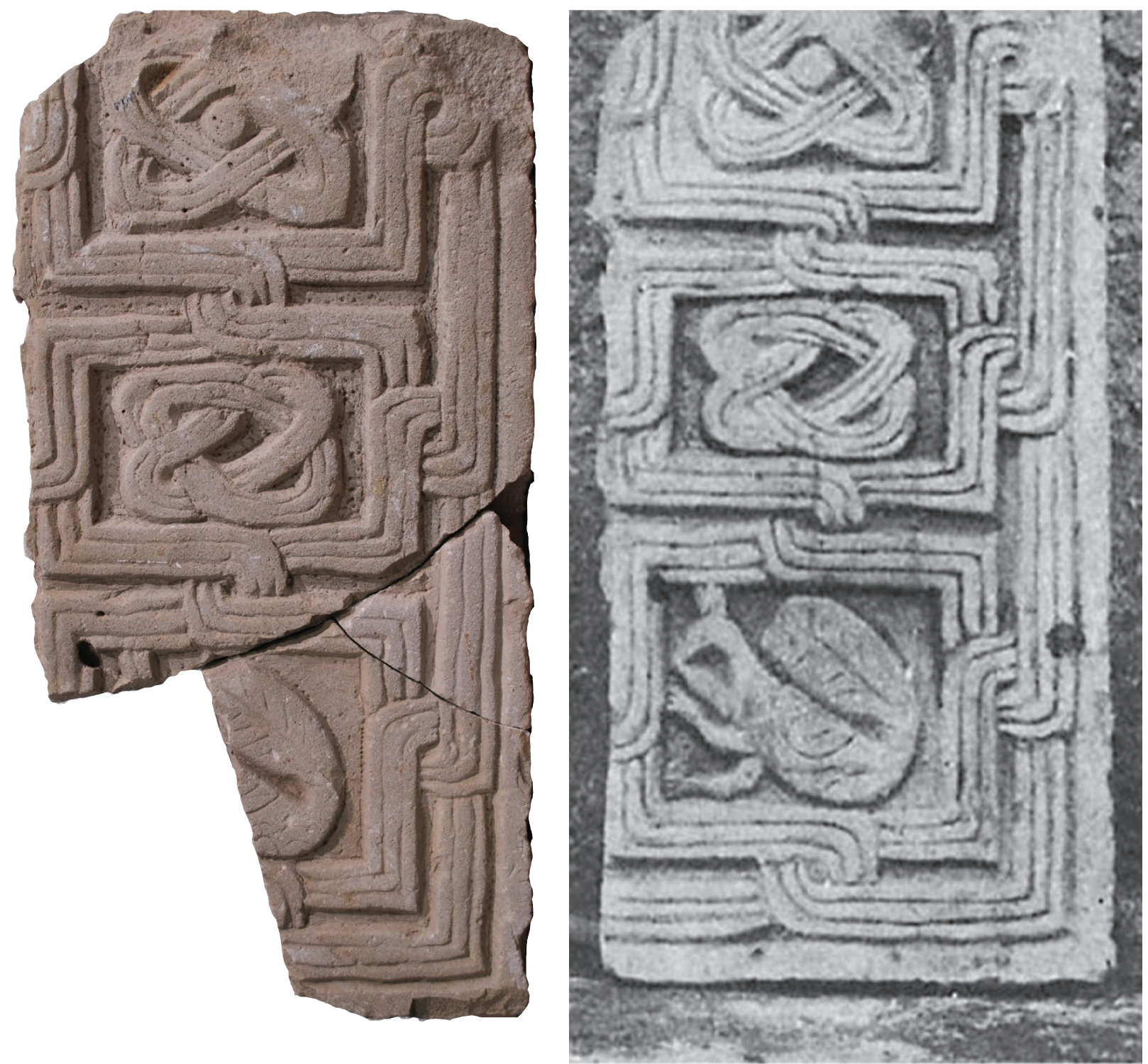

Fig. 1 - a) Arbe, lapidario, frammento di pluteo altomedievale (foto: P. Vedovetto) b) fotografia dello stesso pluteo al momento del suo rinvenimento (da: W. Schleyer, 1914, p. 117)

irriconoscibile. Le due zampe, che ricordano quelle di un animale piuttosto che di un uccello, sono tozze, simili a colonne dai contorni sommari sulle quali si riconoscono distintamente tre artigli. Il corpo è decorato con incisioni circolari e diritte, mentre la coda è resa in modo maldestro con incisioni poco profonde formanti il motivo a spina di pesce. È proprio dal punto di vista iconografico e simbolico che questa rappresentazione suscita maggior interesse.

Sul motivo raffigurato nella cornice rettangolare, eccezionalmente raro sulla costa adriatica orientale così come nella scultura altomedievale in genere, allo stato attuale degli studi non è stato scritto nulla né è stata formulata alcuna interpretazione. Inoltre, non è certa neppure la datazione che non è stata ancora definita con l'ausilio di un'approfondita e seria analisi. Del resto non si conosce neanche la bottega di provenienza di tale pluteo e altresì non ne è stata accertata l'appartenenza a qualche recinzione presbiteriale di una chiesa di Arbe.

L'origine del manufatto, per o meno stando alla classificazione attuale attribuitagli presso il lapidario di Arbe, appare altrettanto ignota. Quando Schleyer pubblicò il pluteo in forma più completa rispetto a quella odierna, a margine aggiunse di averlo rinvenuto nel cortile presso la chiesa di "San Marino". Indicazione forse da interpretare con il sito ove in passato sorgeva la chiesa di S. Martino 
che, secondo lo studioso, restituì alcuni frammenti di scultura altomedievale 3 . Appare dunque molto probabile che il pluteo fosse parte integrante del cancello presbiteriale della scomparsa chiesa di S. Martino ma non è detto che tale ipotesi sia necessariamente esatta. Visto che ad Arbe i rinvenimenti riferibili alla scultura altomedievale sono alquanto esigui, l'esemplare in questione non può essere correlato a nessun altro frammento, né per modalità esecutive né per composizione, utilizzo dei motivi decorativi, dettagli. Per questi motivi al momento risulta difficoltoso determinare l'ubicazione originaria del manufatto. Per accentuare ulteriormente tale dubbio va detto che l'unico elemento di arredo liturgico ascrivibile con più certezza alla chiesa di S. Martino è rappresentato da un pilastro completo (rimasto a lungo inserito come spolia in una costruzione sorta al posto della chiesa scomparsa) che, dal punto di vista esecutivo, appartiene indubbiamente alla scultura che ornava la cattedrale di Arbe ${ }^{4}$. Non è escluso, quindi, che il pilastro e di conseguenza anche il pluteo in questione potessero essere collocati in un secondo tempo nel luogo di rinvenimento nei pressi della chiesa di S. Martino della quale non si conosce quasi nulla, a parte l'ubicazione e il fatto che gli ultimi resti dell'edificio furono smaltiti all'inizio del XX secolo ${ }^{5}$. Si deve aggiungere, inoltre, la considerazione che le uniche analogie tra il pluteo e qualsiasi altra scultura di Arbe si possono solo intuire e intravedere su uno dei lati del ciborio della cattedrale. Tali affinità si esprimono solo nell'utilizzo di maglie triviminee quadrate e rettangolari nella composizione, un motivo piuttosto raro nell'ambito della scultura altomedievale. Per tutti questi motivi la provenienza del pluteo continua a rimanere una questione aperta ${ }^{6}$.

La decorazione descritta nella cassetta angolare del pluteo, rappresentata da un animale di aspetto insolito quasi mai presente nella scultura altomedievale della sponda adriatica orientale e nell'ambito territoriale contermine. In alcune sommarie pubblicazioni la figura veniva trattata come un pavone senza alcuna ulteriore riflessione sul suo aspetto inusuale ${ }^{7}$. I pavoni venivano sempre rappresentati con la coda diritta, mentre l'animale in questione presenta una coda piegata verso l'alto che segue la curva della colonna vertebrale. Secondo il parere di chi scrive tale dettaglio è un fatto imprescindibile per la definizione dell'animale come pavone. Quest'ultimo è dotato di normali zampe da uccello con unghie, mentre l'essere qui rappresentato, a prescindere dalla carente qualità della vecchia fotografia, dall'esecuzione goffa e dalla sommarietà della rappresentazione, presenta le zampe di un predatore con accentuati ingrossamenti dei muscoli, mostra tre artigli chiaramente visibili, oltre ad un'articolazione di una delle due zampe atipica per un uccello. Alla sommità della testa con un occhio enfatizzato non vi è una corona, come sarebbe normale per la simbologia di questi volatili, ma piuttosto due orecchie staccate dal capo e visibili ancor oggi sul frammento pervenuto. Risulta difficile giudicare dalla fotografia datata, tanto più che il rilievo è danneggiato proprio in quel punto, ma l'oggetto che spunta dalla bocca dell'animale sicuramente non assomiglia ad un grappolo d'uva, usuale per la rappresentazione di un pavone. Il sottile e allungato oggetto potrebbe essere la lingua, ma potrebbe essere che sia in realtà la zampa con la quale l'animale sorregge qualcosa in prossimità della bocca. Se questa ipotesi dovesse dimostrarsi giusta, allora sul rilievo sarebbero rappresentate tre zampe. In ogni caso, per quanto qualunque di queste varianti sia esatta, fatto che purtroppo non si riuscirà mai a verificare, per l'interpretazione di questo essere composito risultano essenziali tre dettagli: la coda piegata verso l'alto e all'indietro, le zampe di un predatore e la testa dotata di orecchie.

\footnotetext{
${ }^{3}$ SCHLEYER, op. cit., p. 110.
}

${ }^{4}$ Si veda M. JURKOVIĆ, Quando il monumento diventa documento. Una bottega lapicida del Quarnero, in Alla ricerca di un passato complesso. Contributi in onore di Gian Pietro Brogiolo per il suo 70esimo compleanno, Zagreb - Motovun 2016, p. 231-242.

${ }^{5}$ M. DOMIJAN, op. cit., p. 52.

${ }^{6}$ T. MARASOVIĆ, op. cit., p. 125, attribuisce il pluteo addirittura al convento di S. Eufemia a Kampor, seppure non sia chiara l'origine di tale dato. Inoltre, nel sito di S. Eufemia non è stata appurata l'esistenza di nessuna chiesa di età altomedievale o di epoche precedenti nonostante il fatto che all'interno del convento siano venuti alla luce alcuni frammenti di scultura preromanica sotto forma di spolia.

${ }^{7}$ In tal modo lo ha definito M. JARAK, op. cit., p. 92. 

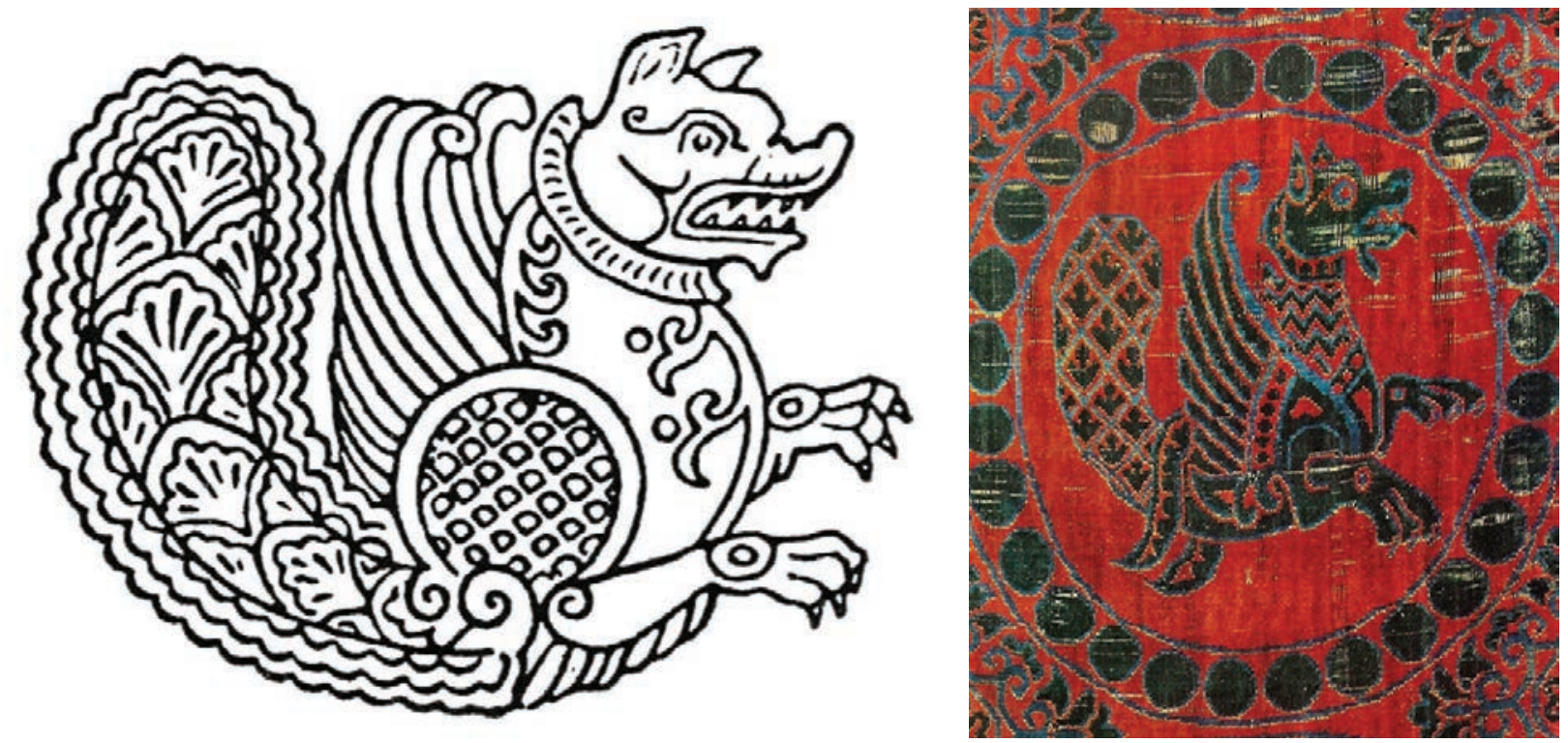

Fig. 2. Senmurv: a) Tāq-e Bostān, Iran (VI - VII secolo) (da Comparetti 2006, fig. 2, p. 196; b) Firenze, Museo Nazionale del Bargello, tessuto in seta, Senmurv, secolo VI-VII (da S. Riccioni, HAM 22, 2016, fig. 20)

È del tutto chiaro che si impone l'identificazione dell'essere composito, con ogni probabilità mitologico, a prescindere dall'entità del danno, dalla sommarietà dell'esecuzione e dalla limitazione dell'inquadratura. L'unico animale che corrisponde alla descrizione sarebbe il senmurv, essere ibrido che nella variante primitiva presentava la testa canina con la lingua stesa, le zampe di leone e la coda di pavone (fig. $2 \mathrm{a}, \mathrm{b})^{8}$. Sulla provenienza di tale essere, sulle sue trasformazioni e, successivamente, sui suoi trasferimenti in altre zone al di fuori di quella originaria, sussiste un'ampissima bibliografia. In breve, stando alle conoscenze odierne lo pseudo-senmurv, come quello che si può vedere sui rilievi nel sito di Tāq-e Bostān nell'Iran, si trasferì nei territori bizantini e da lì, soprattutto durante la dinastia macedone, verso Occidente attraverso i disegni intessuti nella seta ${ }^{9}$. Andrebbero aggiunti anche i prodotti di oreficeria, anch'essi frequente oggetto di scambi commerciali, come quelli che sono stati restituiti dal deposito a Veliki Preslav in Bulgaria ${ }^{10}$. Non è necessario parlare qui del significato di questo essere e delle sue trasformazioni, ossia delle contaminazioni del suo significato, ma si deve ribadire che in una delle varianti gli viene attribuito il concetto della Suprema Gloria che facilitò il suo trasferimento verso l'Islam e il Cristianesimo ${ }^{11}$.

Tuttavia, il pluteo di Arbe con la rara rappresentazione del senmurv (fig. 3b) non è tanto isolato nella scultura altomedievale del territorio, poiché esiste un pluteo frammentario analogo in ogni dettaglio proveniente da Neviđane sull'isola di Pasmano (fig. 3a) ${ }^{12}$. Del manufatto si conserva il tratto sinistro quasi nella sua intera altezza. Il campo centrale, sotto la cornice aggettante, consiste di una

\footnotetext{
${ }^{8}$ M. COMPARETI, The So-called Senmurv in Iranian art: A Reconsideration of an Old Theory, in Loquentes linguis. Studi linguistici erientali in onore di Fabrizio A. Pennacchietti, a cura di P. G. BORBONE, A. MENGOZZI, M. TOSCO, Wiesbaden, 2006, p. 189.

${ }^{9}$ A. GRABAR, Le rayonnement de l'art sassanide dans le monde chrétien, In La Persia e il Medioevo, Roma 1971, pp. 679707; S. RICCIONI, La rappresentazione della natura tra ornamento e narrazione. Il bestiario di Roma tra i secoli XI X XII, in Medioevo: natura e figura. La raffigurazione dell'uomo e della natura nell' arte medievale, Atti del convegno internazionale di studi dell'AISAME (Parma 20-25, sett. 2011), a cura di A. C. Quintavalle, Milano, 2015, pp. 342-343; Ibidem, Dal ketos al senmurv? Mutazioni iconografiche e transizioni simboliche del ketos dall'Antichità al Medioevo (secolo XIII), Hortus Artium Medievalium 22, pp. 130-144.

${ }^{10}$ Si veda in Otto der Grosse. Magdeburg und Europa, Band II, Katalog, kat. N. VI.58b, Mainz, 2001, pp. 488.

${ }^{11}$ M. COMPARETI, op. cit., 192.

${ }^{12}$ È stato pubblicato da F. RADIĆ, Ostanci starohrvatske crkvice S. Mihovila u Nevidjanima na otoku Pašmanu, Starohrvatska prosvjeta, serie I, VI/3-4, Knin, 1901, pp. 84-86.
} 

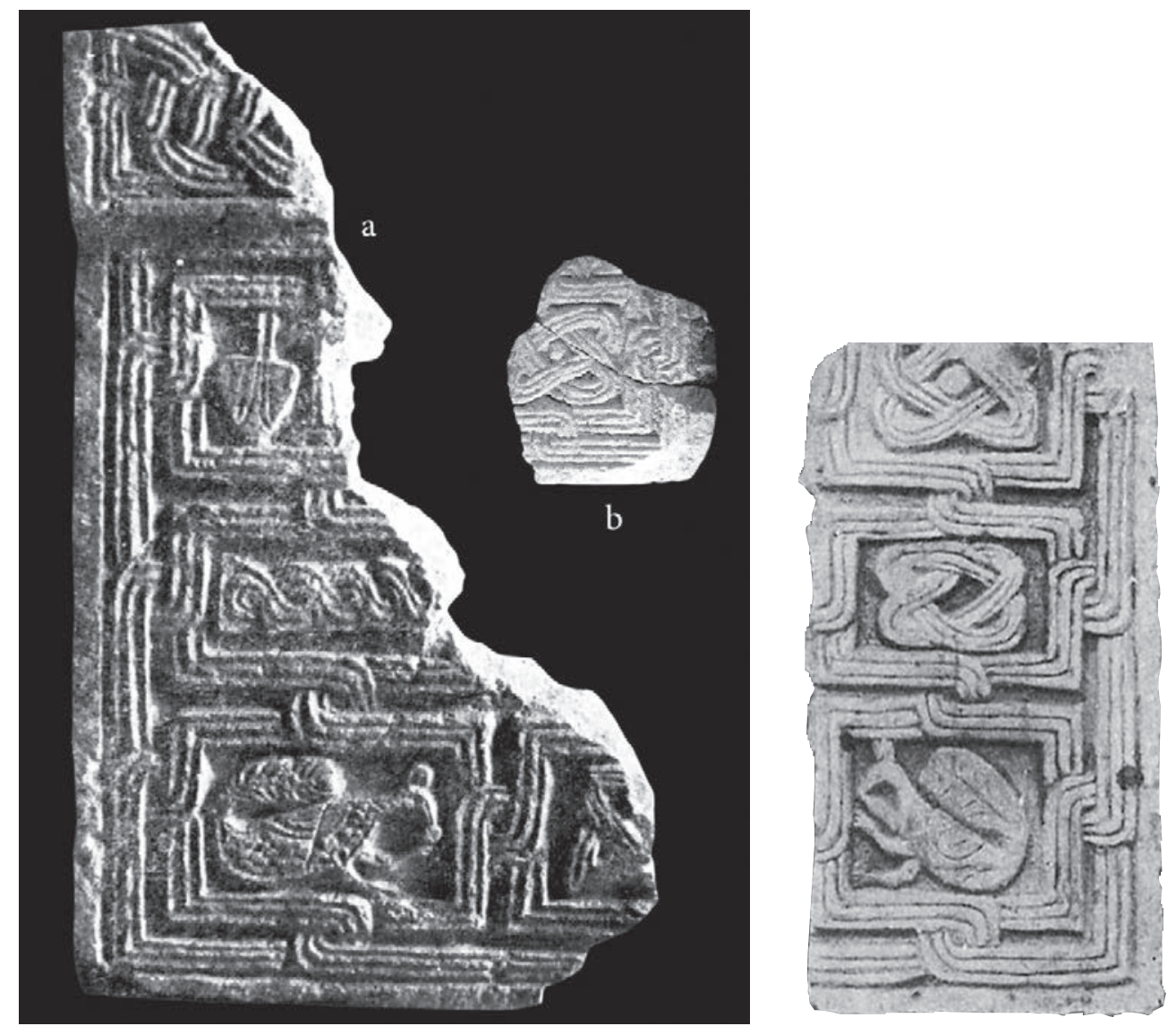

Fig. 3. plutei a) Nevidane (foto I. Josipović), b) Arbe (da Schleyer)

rete di maglie quadrangolari triviminee, probabilmente in origine nove, posizionate orizzontalmente e annodate tra loro e con il nastro bisolcato che incornicia la composizione. Le maglie rettangolari presentano diversi riempitivi. Partendo dall'alto vi è una foglia schematizzata e la porzione ridotta di un giglio, al centro si trova una matassa a due capi e in basso un senmurv. La maglia successiva, conservatasi per metà, verosimilmente era campita da un nodo trivimineo. Si è conservato anche un frammento minore, non collegabile con il tratto descritto del pluteo, recante il nodo di Salomone con al centro un bottone. Quindi, sui plutei di Arbe e Neviđane ricorrono due motivi identici, ovvero il nodo di Salomone e il senmurv. L'animale ibrido del pluteo di Neviđane, proprio come nel caso di Arbe, è stato identificato come pavone con la coda piegata in alto solo per lo spazio ridotto nella maglia rettangolare nella quale è collocato ${ }^{13}$. La composizione e la distribuzione di elementi sono identiche su entrambi i plutei. Lo stesso si può affermare per la modalità di esecuzione con il fondo piuttosto profondo, il trattamento morbido e stondato dei bordi e la resa bassa dei motivi decorativi. Pertanto, ambedue i manufatti dovevano essere prodotti della stessa bottega lapicida ${ }^{14}$.

${ }^{13}$ RADIĆ, op. cit. P. 85. Tuttavia, studiando in tempi recenti la scultura della Dalmazia settentrionale I. JOSIPOVIĆ, Predromanički reljefi na teritoriju Sklavinije Hrvatske izmedu Zrmanje i Krke do kraja 9. stoljeća (I rilievi preromanici sul territorio del ducato croato medievale tra i fiumi Zrmanja e Krka fino alla fine del IX secolo), tesi di dottorato, Zagreb, 2013, p. 30, descrive il rilievo sottolineando "l'inusuale pavone la cui coda è piegata lungo la spina dorsale come se si trattasse di uno scoiattolo e non di un uccello", intuendo in tal modo la peculiarità della rappresentazione. Nel testo più recente (I. JOSIPOVIĆ, Il Maestro degli amboni zaratini, Hortus Artium Medievalium 22, 2016, pp. 443-450), Josipović accoglie l'identificazione dello scrivente della rappresentazione come senmurv.

${ }^{14}$ L'affinità dei frammenti è tale (dell'esemplare di Arbe è pervenuto il terzo destro e di quello di Pasmano il terzo sinistro) da poter ipotizzare che si tratta dello stesso insieme. Naturalmente, non si può accertare tale supposizione senza una dettagliata analisi della superficie del rilievo. Nell'ambito di questa riflessione va ribadita l'ipotesi che il pluteo di Neviđane, nonché gli altri elementi di arredo liturgico rinvenuti in quel sito, provengano da Zara e che furono trasferiti come spolia sull'isola di Pasmano. Sull'origine della scultura di Neviđane si veda I. PETRICIOLI, 


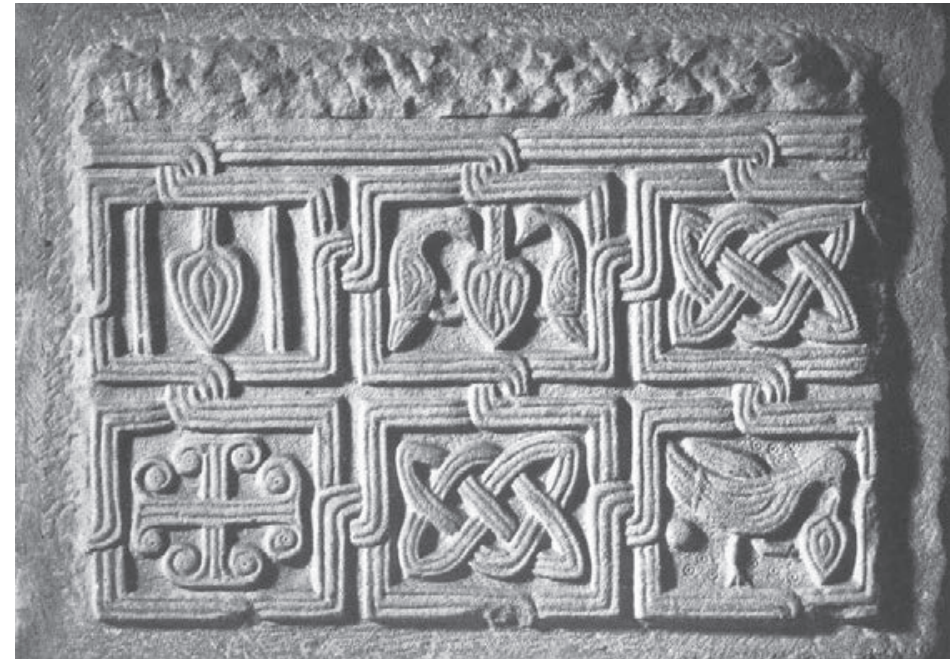

Fig. 4. Cividale, Museo Nazionale, pluteo (da Corpus X, 339)

L'officina alla quale appartiene il pluteo di Neviđane è stata individuata di recente. Si tratterebbe della bottega che I. Josipović ha definito come Il maestro degli amboni di Zara ${ }^{15}$. Stando all'autore, tale lapicida lavorò sull'arredo liturgico nella cattedrale di Zara, nella chiesa di S. Crisogono a Zara e nella chiesa di S. Martino a Predrosi (Pridraga) presso Novegradi. Una delle caratteristiche dell'opus del maestro zaratino sono le composizioni collocate all'interno delle reti di maglie quadrate e rettangolari, l'utilizzo frequente della figura umana, il contrasto tra lo sfondo profondo, il trattamento morbido dei bordi dei motivi triviminei e le linee incise poco profonde. Alle opere di questo maestro scalpellino, quindi, può essere associato anche il pluteo di Arbe.

Ai fini della datazione della bottega è stato utile il confronto tra gli amboni di Zara e la notissima lastra di Sigualdo di Cividale ${ }^{16}$. Oltre a tale indubbio punto fermo, per la determinazione cronologica si dovrebbe riflettere sulla provenienza dei lapicidi e, a tal proposito, ribadire che a Cividale si possono trovare gli stessi schemi compositivi e, addirittura, qualche dettaglio di lavorazione identico, per esempio l'esecuzione delle foglie (fig. 4) ${ }^{17}$.

Per la datazione del periodo di attività dell'officina del Maestro degli amboni di Zara, al quale ora viene attribuito anche il pluteo di Arbe, si propone la fine dell'VIII o l'inizio del IX secolo; in ogni caso un orizzonte cronologico precedente la pace di Aquisgrana dell'812, quando la mobilità delle maestranze tra le diverse entità politiche si fece più difficoltosa e quando le gerarchie ecclesiastiche divennero parte di mondi diversi ${ }^{18}$. A favore di tale ipotesi depone anche l'identificazione dello scalpellino sull'isola di Arbe e ulteriori paralleli di Cividale denunciano il breve periodo della presenza carolingia nelle città dalmate nel primo decennio del IX secolo.

Al momento il pluteo di Arbe rimane un esempio isolato dell'opus della bottega lapicida attiva sull'isola. Tuttavia, già nella parte introduttiva sono state sottolineate le affinità generali nella composizione delle maglie quadrate e rettangolari su uno dei lati del ciborio di Arbe ${ }^{19}$. L'analisi comparativa dei particolari e dei motivi specifici è praticamente impossibile poiché il pluteo e il ciborio non

Predromanički ambon zadarske katedrale i srodna skulptura, in Starohrvatska spomenička baština. Rađanje prvog hrvatskog kulturnog pejzaža, (ed.) M. Jurković, T. Lukšić, Zagreb, 1996, p. 211, che la attribuisce alla cattedrale di Zara. Dall'altro canto N. JAKŠIĆ - E. HILJE, Umjetnička baština Zadarske nadbiskupije - Kiparstvo I (od IV. do XVI. stoljeća), Zadar, 2008, pp. 26, 86-94, cat. n. 011-015, ritengono che la scultura di Neviđane appartenne alla chiesa zaratina di S. Crisogono. Per il presente dibattito è essenziale che gli studiosi concordano sul fatto che tutta la scultura rinvenuta a Neviđane fosse originariamente appartenuta a qualche chiesa di Zara.

${ }^{15}$ Sulla traccia delle proposte più datate (I. PETRICIOLI, op. cit., pp. 209-214), 1'opus della bottega fu minuziosamente analizzato e denominato da I. JOSIPOVIĆ, Predromanički reljefi, op. cit., pp. 21-35; IBIDEM, Il Maestro degli amboni zaratini, op. cit.

${ }^{16}$ I. PETRICIOLI, op. cit.; I. JOSIPOVIĆ, Il maestro..., op. cit.

${ }^{17}$ A. TAGLIAFERRI (a cura di), Corpus della scultura altomedievale X, Le diocesi di Aquileia e Grado, Spoleto, 1981, p. 226, t. c, fig. 339.

${ }^{18}$ I. JOSIPOVIĆ, op. cit.

${ }^{19}$ In merito al ciborio si veda P. VEŽIĆ - M. LONČAR, Hoc tigmen. Ciboriji ranog srednjeg vijeka na tlu Istre i Dalmacije, Zadar, 2009, pp. 52-56; M. JARAK, op. cit., p. 89. 


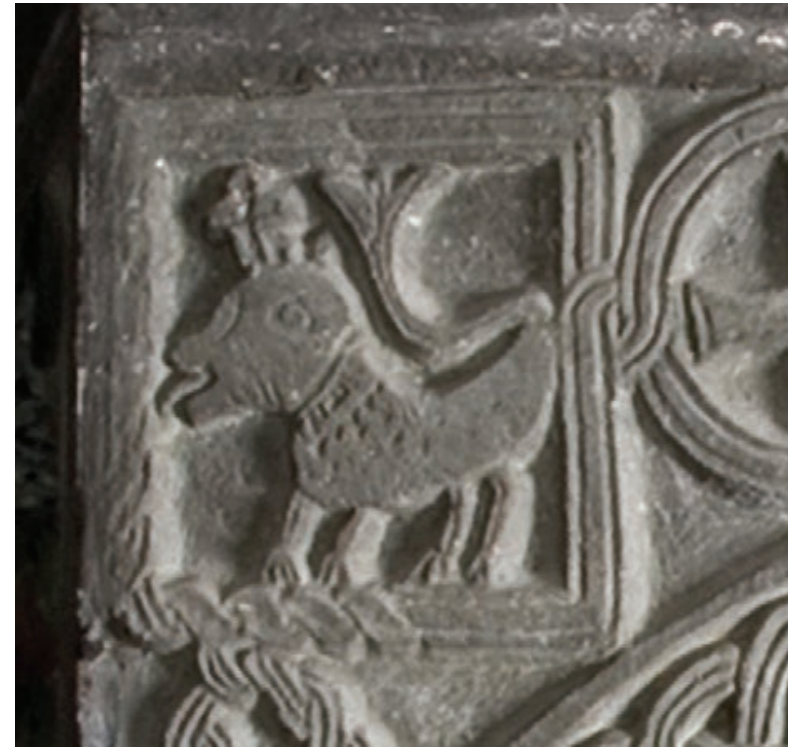

Fig. 5. Arbe, ciborio, dettaglio (foto Z. Alajbeg)

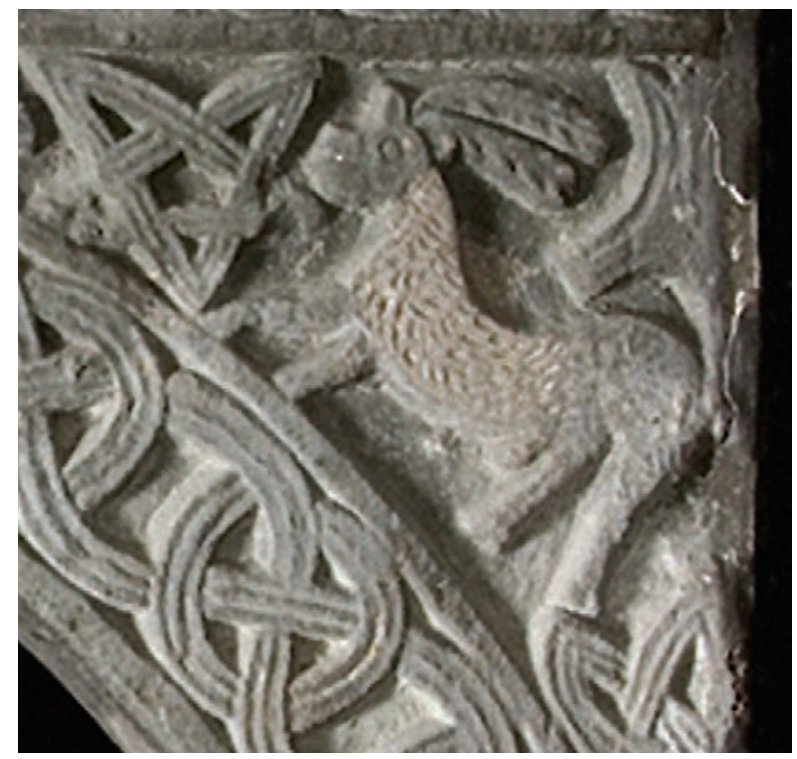

Fig. 6. Arbe, ciborio, dettaglio (foto Z, Alajbeg)

recano nemmeno un solo motivo comune e, inoltre, si dovrebbe attendere l'intervento di pulizia del ciborio dagli strati di vernice e di aggiunte in stucco. L'idea del nesso tra i due manufatti si basa, dunque, esclusivamente sulle analogie generiche e la modalità di lavorazione delle superfici. Comunque, dopo l'attribuzione del pluteo all'attività di un'officina identificata in precedenza, la possibilità di analisi comparativa si apre attraverso il confronto con le sculture realizzate dalla bottega da cui uscì il pluteo in questione. In tal senso va ribadito che sui lati del ciborio sono rappresentate alcune figure di quadrupedi. In una maglia quadrata vi è un animale a quattro gambe con la coda molto alta. La resa delle sue zampe munite di artigli indica chiaramente che si tratta di un predatore, molto probabilmente un leone (fig. 5). Si nota anche la caratteristica lavorazione della superficie, in quanto solo sulla metà anteriore della figura zoomorfa è resa la criniera con linee incise, mentre la metà posteriore è completamente liscia. Un altro dettaglio caratteristico è il dorso inarcato. Entrambi i dettagli appena descritti si trovano nelle rappresentazioni di animali del Maestro degli amboni di Zara sugli esempi di Pridraga e di Zara. Il manufatto di Pridraga presenta la tipica superficie liscia ${ }^{20}$. Il quadrupede di Arbe (fig. 6) è difficilmente definibile ma, a giudicare dalla lavorazione della superficie della pietra mediante sottili incisioni che suggeriscono il pelo, si potrebbe trattare di un predatore. Sopra la testa dell'animale vi sono due motivi quasi irriconoscibili, forse qualche tipo di corna, collocati vicino alle orecchie leonine. In ogni caso la figura zoomorfa è un ungulato come si può constatare dal tratto terminale della gamba che differisce da quella degli artigli del leone rappresentato nella maglia precedente ${ }^{21}$. In base a quanto esposto qui si tratta di un animale ibrido il cui significato dovrà essere ancora definito. L'elemento che collega questo rilievo con quelli di Pridraga è il fallo enfatizzato dell'animale ${ }^{22}$. Seppure i confronti riportati sono insufficienti per poter asserire con certezza che il ciborio di Arbe appartenga alla stessa bottega, si devono tenere a mente le analogie generiche, l'identicità di alcuni dettagli e le modalità esecutive delle superfici finché non compariranno nuove scoperte che potranno ampliare il numero dei motivi comparabili. Tale paragone risulta ancor più difficile quando si tratta di cibori, poiché questi nella maggior parte dei casi presentano un determinato e rigidamente limitato repertorio di motivi decorativi, pertanto questo argomento rimane aperto ad ulteriori studi e ricerche.

\footnotetext{
${ }^{20}$ I. JOSIPOVIĆ, Il maestro, op. cit, fig. 6.

${ }^{21}$ Appare interessante che gli studiosi vedono l'animale in modo diverso. Secondo M. JARAK (op. cit., 89) si tratta di un cervo, P. VEŽIĆ (P. VEŽIĆ - M. LONČAR, op.cit., p. 55) vi vede un caprone e un unicorno, tesi accolta da T. MARASOVIĆ (op. cit., p. 142), sebbene chi scrive non riesca a visualizzare questi due animali.

22 In merito agli esempi di Pridraga si veda I. JOSIPOVIĆ, Il maestro, op. cit, fig. 6.
} 
Con questo breve contributo, dedicato al mio professore Igor Fisković, mi auguro di aver intavolato un nuovo capitolo di studio. Di fatto, nell'ambito della scultura altomedievale non si è soliti discutere di iconografia, visto che essa rappresenta un argomento raro e secondario per il semplice motivo che sulle realizzazioni di tale periodo predomina l'intreccio vimineo geometrico, i motivi vegetali e il consueto repertorio di origini cristiane facilmente distinguibili. Le conoscenze sull'esistenza di rari, ma profondamente diversi motivi simbolici come il senmurv, impongono un ampliamento di campi di ricerca anche su quegli aspetti che sino ad oggi apparivano meno importanti o addirittura insignificanti ${ }^{23}$.

\section{JEDAN RIJEDAK IKONOGRAFSKI MOTIV NA RANOSREDNJOVJEKOVNOJ SKULPTURI - SENMURV IZ RABA I NEVIĐANA}

U lapidariju grada Raba izložen je fragment ranosrednjovjekovnog pluteja vrlo zanimljive dekoracije. Riječ je o desnoj trećini pluteja, na kojemu je kompozicijska shema niza troprutih pravokutnika povezanih sa svih strana čvorovima (fig. 1a). Rubna tropruta traka povezuje sve pravokutnike u jedinstvenu kompoziciju tako da iz te trake ritmički izlaze čvorovi koji love sredinu svake stranice svakog od pravokutnika. Danas su sačuvana samo dva cjelovita polja i jedan polovično. Dva pravokutnika ispunjena su troprutim Salomonovim čvorom, od kojih jedan u sredini ima plastički istaknuto oko. Na staroj fotografiji još uvijek cjelovit donji, ugaoni pravokutnik sa zoomorfnim prikazom. Upravo je taj prikaz u svom ikonografskom i značenjskom izričaju i najzanimljiviji.

Motiv u ugaonoj kaseti pluteja zagonetna je životinja neobična izgleda, kakva se gotovo nikad ne susreće u ranosrednjovjekovnoj skulpturi istočnojadranske obale, a i šire. To nije prikaz pauna kako ga se dosad tretiralo, jer su prikazi pauna uvijek s ravnim repom, dok je ovaj naš zavijen prema gore prateći kralježnicu životinje. Po mojem je sudu to nepremostiva činjenica u definiranju životinje kao pauna. Nadalje, paun dakako ima normalne ptičje noge i kandže, no ove naše, bez obzira na staru lošu fotografiju, bez obzira na nezgrapnost izvedbe, i bez obzira na sumarnost prikaza, više liče na šape neke grabežljive životinje s pandžama, s naglašenim zadebljanjima mišića, s jasno vidljive tri kandže na šapi, i konačno s lomom u zglobu jedne šape, što se doista vrlo rijetko vidi na ptičjim nogama. $\mathrm{Na}$ kraju, glava, s naglašenim okom, na vrhu nema krunu, kako bi to bilo normalno za simboliku paunova, već dva odvojena uha. Teško je suditi po staroj fotografiji, no predmet koji izlazi iz usta životinje sasvim sigurno svojim oblikom nije grozd, što bi za pauna bilo uobičajeno. Tanki izdužen predmet je moguće jezik životinje. No moguće je da je predmet koji naizgled izlazi iz usta zapravo šapa kojom životinja pridržava nešto pri ustima. Ukoliko je to točno, na reljefu su prikazane tri noge. Koja god varijanta bila točna, što se nažalost neće moći provjeriti, tri su detalja za tumačenje kompozitnoga bića ključna: rep svinut prema gore i unatrag, noge grabežljivice, glava s ušima. Jedina je životinja koja odgovara opisu senmurv, hibridno biće, u izvornom obliku pseće glave, često isplažena jezika, lavljih šapa i paunovog repa (sl. 2a, b).

\footnotetext{
${ }^{23}$ In questa direzione si muove anche il recente volume di A. MILOŠEVIĆ, Tragovi starih vjerovanja u kršćanstvu ranog srednjeg vijeka - Traces of Ancient Beliefs in Early Medieval Christianity, Split, 2013, nel quale l'autore tratta proprio la scultura del Maestro degli amboni di Zara, il motivo del fallo presente su alcuni rilievi realizzati da tale officina collegandoli con le credenze slave precristiane. Per avviare un nuovo dibattito, aggiungiamo che il motivo del senmurv analizzato anche in questa opera in una delle trasmutazioni può avere gli stessi collegamenti. Il senmurv secondo alcune interpretazioni, infatti, potrebbe avere nessi con la divinità slava Simargl in merito alla quale, a dire il vero, le opinioni divergono, anche se la stessa fu inserita nell'elenco delle divinità del principe di Kiev Vladimir (M. COMPARETI, op. cit., p. 194). Il nome Simargl deriva chiaramente da Simorgh, che è il nome persiano del senmurv nella variante della divinità con sembianze di uccello.
} 
Rapski plutej s rijetkim prikazom senmurva u ranosrednjovjekovnoj skulpturi nije posve usamljeni primjerak u širem okruženju. Naime, pluteju iz Raba (fig. 3b) u svakom je detalju sličan fragmentirani plutej iz Neviđana na otoku Pašmanu (fig. 3a). Dva su motiva na plutejima iz Raba i Neviđana identična: Salomonov čvor i senmurv. Kompozicija oba pluteja, raspored elemenata, identična je. Način klesanja na oba pluteja, sa dubljom pozadinom, mekim i zaobljenim tretiranjem rubova, plitkim klesanjem motiva identični su. Oba bi prema tome trebala biti djelo iste klesarske radionice.

Klesarska radionica kojoj pripada plutej iz Neviđana nedavno je definirana - prepoznat je kao dio opusa radionice koju je I. Josipović nazvao Majstor zadarskih ambona. Taj je majstor radio na liturgijskoj opremi katerdrale u Zadru, crkve sv. Krševana u Zadru, crkvi sv. Martina u Pridrazi kod Novigrada. Karakteristično za djelatnost majstora su kompozicije unutar mreže kvadratnih i pravokutnih polja, korištenje ljudskog lika, kontrast između duboke pozadine i mekog tretiranja rubova troprutih motiva, često plitko urezane linije. Tom se opusu sada svakako može pridružiti i rapski plutej.

Za datiranje te radionice poslužile su komparacije između zadarskih ambona i stručnoj javnosti nadaleko poznate Sigualdove ploče iz Cividalea. Osim tog nedvojbenog uporišta za dataciju, moralo bi se promišljati i o provenijenciji samih majstora. U tom razmišljanju valja upozoriti kako se u Cividaleu mogu pronaći iste kompozicijske sheme, čak i koji identično obrađeni detalj, poput razrade listova (fig. 4).

Što se pak datiranja djelatnosti radionice Majstora zadarskih ambona tiče, kojem je sada pridodan i rapski plutej, predloženo je vrijeme kraja 8. ili ranije 9. stoljeće, svakako prije aachenskog mira 812. godine, kada bi mobilnost klesara između različitih političkih cjelina bila otežana, i kada su crkvene hijerarhije pripale ipak različitim svjetovima. Tom u prilog svakako ide i prepoznavanje majstora na otoku Rabu, a dodatne paralele iz Cividalea svakako upućuju na kratak period karolinškog prisustva u dalmatinskim gradovima u prvom desetljeću 9. stoljeća.

Zasad plutej iz Raba ostaje usamljen primjerak opusa navedene klesarske radionice na otoku. Međutim, opće sličnosti u komponiranju kvadrata i pravokutnika nalazimo na jednoj od stranica rapskog ciborija. Komparativna analiza detalja i specifičnih motiva praktički je nemoguća jer plutej i ciborij nemaju baš niti jedan zajednički motiv, a k tome, moralo bi se pričekati čišćenje ciborija od premaza i štuko dodataka. Mišljenje o njihovu povezivanju temelji se isključivo na generičkim sličnostima i načinu obrade plohe. No, nakon što je plutej pripisan djelatnosti jedne ranije definirane radionice, mogućnost komparativnih analiza detalja otvara se komparacijom s drugim skulpturama radionice kojoj naš plutej pripada. Valja naglasiti da se na stranicama ciborija prikazuje nekoliko četveronožnih životinjskih likova. U jednom kvadratnom polju prikazan je četveronožac jako uzdignuta repa. Razrada šapa sa pandžama jasno pokazuje da je riječ o grabežljivcu, najvjerojatnije lavu (fig. 5). Karakteristična je obrada površine - samo je na prednjoj polovici životinje uparanim linijama ukazano na grivu. Stražnja je polovica glatka. Drugi karakterističan detalj su povinuta leđa. Oba ta detalja nalazimo na prikazima životinja Majstora zadarskih ambona, na primjerima iz Pridrage i Zadra, a karakterističnu glatku površinu u Pridrazi. Drugi prikazani četveronožac (fig. 6) teško je odrediv: sudeći po obradi površine tankim urezima koji sugeriraju dlaku, mogao bi biti grabežljivac; iznad glave životinje stoje vrlo slabo raspoznatljiva dva motiva, moguće neka vrst rogova, a uz uši koje su lavlje i lice koje liči na ljudsko; u svakom slučaju riječ je o kopitaru, što pokazuje obrada nogu različita od pandži lava na prethodno opisanoj arkadi. Po svemu sudeći i ovdje je riječ o hibridnoj životinji, čije će ikonografsko značenje tek trebati odrediti. No, ono što taj reljef povezuje sa onima iz Pridrage je jasno naglašen falus životinje. Iako su navedene komparacije nedovoljne za potpuno uvjerenje da bi i rapski ciborij mogao pripadati istoj radionici, svakako valja imati na umu generičke sličnosti, identičnosti pojedinih detalja i način obrade površine, očekujući da neki novi nalazi prošire broj komparabilnih motiva.

Ključne riječi: ranosrednjovjekovna skulptura, ikonografija, senmurv, klesarske radionice 